Brazilian Journal of Microbiology (2009) 40: 450-454

ISSN 1517-8382

\title{
OCCURRENCE OF CAMPYLOBACTER JEJUNI AND CAMPYLOBACTER COLI AND THEIR BIOTYPES IN BEEF AND DAIRY CATTLE FROM THE SOUTH OF CHILE
}

\author{
Heriberto Fernández*; Marianne Hitschfeld
}

Instituto de Microbiología Clínica, Universidad Austral de Chile, Valdivia, Chile

Submitted: September 14, 2008; Returned to authors for corrections: October 10, 2008; Approved: May 03, 2009.

\begin{abstract}
The prevalence of Campylobacter jejuni and Campylobacter coli and their biotypes in beef and dairy cattle from the South of Chile was established. Campylobacter were statistically more prevalent among beef cattle (35.9\%) than among dairy cattle (21.3\%), being C. jejuni the species most frequently isolated.
\end{abstract}

Key words: Campylobacter jejuni, C. coli, beef cattle, dairy cattle

The thermotolerant species (C. jejuni and C. coli) of the genus Campylobacter are zoonotic bacteria with worldwide distribution. These bacteria are the primary causative agents of diarrhea in humans in industrialized countries, and are important causes of diarrhea in developing countries $(4,8$, $10,16)$.

Reservoirs for $C$. jejuni and C. coli include cows, sheep, pigs, and other species of domestic and wild animals, all of which can be direct or indirect sources of infection for humans. C. jejuni and C. coli are carried as commensal organisms in the intestines of these animals. C. jejuni may also cause abortion in some animal species $(3,4,6,14,16)$.

In the southern Chile, beef and dairy cattle should be considered an important reservoir for Campylobacter contamination of milk, meat, and the environment (6).

Campylobacter should also be considered a veterinary problem in production animals. $C$. jejuni has been reported to cause enteritis in calves and bovine mastitis and C. fetus subsp. fetus is responsible for abortion and infertility in cattle $(1,14)$.

In Southern Chile, it has been demonstrated that free reared domestic laying hens and pet and stray dogs are reservoirs of Campylobacter, and they contaminate the environment where these domestic animals live $(5,6,7)$. However, there is little information on the relevance of cows in the transmission of $C$. jejuni and $C$. coli to humans.

Beef and milk production are important in this part of Chile, and it is therefore necessary to know the prevalence of C. jejuni and C. coli in cows in this geographical area, to establish its isolation frequency, common biotypes, and to determine if there are differences between the carriage for confined dairy cows and for beef cattle raised on grass. 
We studied 300 faecal swab samples collected from cows. These samples were collected at random from 220 cattle going to a slaughter house (Frival Valdivia), and from 80 confined dairy cattle from the same herd, kept indoors.

After collection, samples were transported in Cary-Blair medium (approximately $2 \mathrm{ml}$ ) under refrigeration for a period of no more than 18 hours. Samples were plated out on modified Skirrow agar plates (cit. 5, 6), which were incubated at $42^{\circ} \mathrm{C}$ for 48 hours under microaerobic conditions (6), for the isolation of thermotolerant Campylobacter species (C. jejuni and C. coli). The identification of the species was done with phenotypic tests using the API Campy® (bioMérieux. Marcy/Etoile, France.) test procedure. The biotyping was done using the method described by Lior (11) as adapted for use in our laboratory (6). Statistical evaluation was done through $\mathrm{z}$ test using Epidat 3.1 program (13).

Table 1 shows that $32.0 \%$ of the samples were positive for Campylobacter spp. Significant differences $(p<0.05)$ were found between the highest prevalence rate, observed in beef cattle $(35.9 \%)$, and the lowest prevalence rate found in dairy cattle $(21.3 \%)$. In all sample groups, C. jejuni was the most commonly isolated species (85 strains) with the remaining of the samples being $C$. coli (11 strains).

Within dairy cattle, 15 strains of $C$. jejuni were found, with biotype I showing the highest prevalence $(60.0 \%)$ and biotype II making up the rest (40.0\%). Only two strains of $C$. coli were isolated in this group, corresponding one strain to biotype I and the other, to biotype II.

Seventy strains of $C$. jejuni were isolated from beef cattle. Biotype I was the most frequent (58.6\%), followed by biotype II (18.6\%), biotype III (20\%) and biotype IV (2.9\%).

The two biotypes described for $C$. coli were found, with biotype I composing $66.7 \%$ of the isolates and biotype II making up the rest $(33.3 \%)$. The overall prevalence of Campylobacter spp. was $32.0 \%$, a prevalence that is similar to reports by Fernández (8) in Chile (39.3\%). A higher prevalence rate has been reported by Giacoboni et al (9) in Japan (46.7\%). In addition, lower prevalence rates have been found by Cabrita et al (3) in Portugal (19.5\%), and Tresierra et al (15) in Peru. These results indicate, from the epidemiological stand point that intestinal carriage may be conditioned by the environment in each place. The higher prevalence of $C$. jejuni in relation to $C$. coli is a common pattern that is found in most studies and includes samples isolated from animals and humans $(6,8,16)$.

Bailey et al (2), studing 19 herds in Australia, found that Campylobacter prevalence ranged from $0 \%-24 \%$ for dairy cattle and $0 \%-52 \%$ for pasture beef cattle. Padungtod and Kaneene (12) reported that Campylobacter prevalence was $14 \%$ in dairy cows in Thailand. In the two latter studies $C$. jejuni was also more frequent than C. coli.

The higher prevalence of Campylobacter in beef cattle is an epidemiological event that may be associated to the environment where these cattle have been raised. While beef cattle are raised on pasture and in contact with a diverse environment, dairy cattle are kept in confinement and under better environmental hygienic conditions. A direct correlation between poor environmental hygienic conditions and a higher prevalence rate for Campylobacter was reported by Fernández et al for laying hens (5) and dogs (7).

The fact that four biotypes of $C$. jejuni were isolated from beef cattle while only two biotypes were found in dairy cattle is also a result of the different environmental exposure between these two types of production $(5,7)$. In both group of animals (beef and dairy), biotypes I and II where the most prevalent, and they also happen to be the most prevalent biotypes isolated from other animals and humans in our region (6).

Based on these results, we believe there is a need for further studies aimed at elucidating the sources of 
Fernández, H. et al.

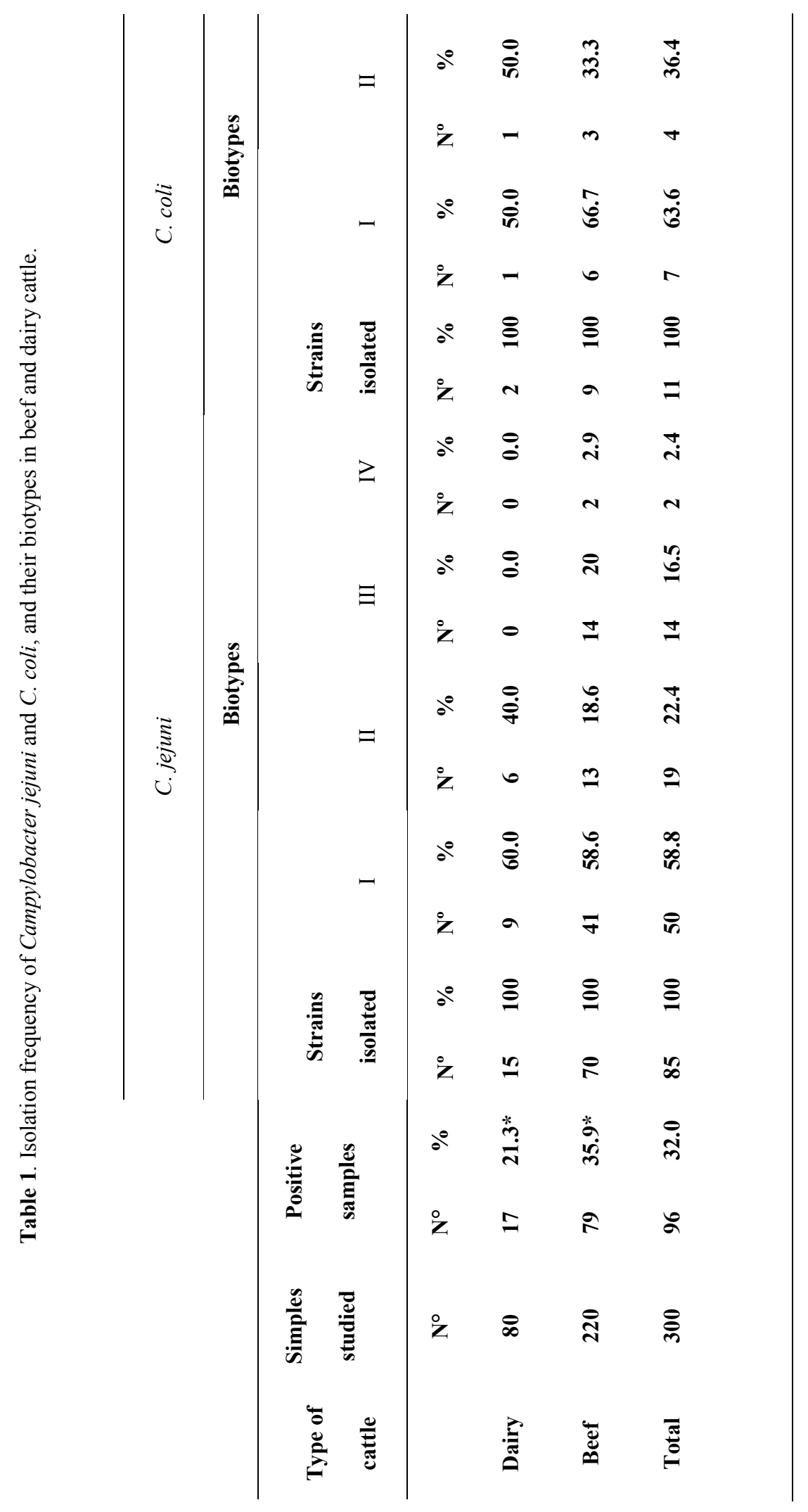


environmental contamination for beef and dairy cattle. In addition, the environment of the processing facilities for these animals and the resulting foods should also be evaluated for the presence of Campylobacter spp. to implement specific control measures designed to improve the safety of these foods.

\section{ACKNOWLEDGMENTS}

Thanks are due to Dr. Janet Corry (University of Bristol) and Dr. Albert Lastovica (University of the Western Cape) for their advices and critical review.

This work received financial support from Grant DID-UACh S-2007-37

\section{RESUMO}

\section{Ocorrência de Campylobacter jejuni e Campylobacter coli e seus biotipos em bovinos de corte e de leite no sul do}

\section{Chile.}

Foi estabelecida a prevalência de Campylobacter jejuni e Campylobacter coli e seus biotipos, em bovinos de corte e de leite do sul do Chile. Campylobacter foi estatisticamente mais prevalente nos bovinos de corte $(35,9 \%)$ do que nos bovinos de leite $(21,3 \%)$, sendo $C$. jejuni a espécie mais frequentemente isolada.

Palavras-chave: Campylobacter jejuni, C. coli, bovinos de corte, bovinos de leite
1. Atabay, H.I.; Corry, J.E. (1998). The isolation and prevalence of campylobacters from dairy cattle using a variety of methods. J. Appl. Microbiol., 84, 733-740.

2. Bailey, G.D.; Vanselow, B.A.; Hornitzk, M.A.; Hum, S.I.; Eamens, G.J.; Gill, P.A; Keith, H.; Walker, K.H.; Cronin, J.P. (2003). A study of the foodborne pathogens: Campylobacter, Listeria and Yersinia, in faeces from slaughter-age cattle and sheep in Australia. CDI, 20, 249256.

3. Cabrita, J.; Rodriges, J.; Bracança, F.; Morgado, C.; Pires, I.; Gonçalves, A.P. (1992). Prevalence, biotypes, plasmid profile and antimicrobial resistance of Campylobacter isolated from wild and domestic animals from Northeast Portugal. J. Appl. Bacteriol., 73, 279285.

4. Coker, A.O.; Isokpehi, R.D.; Thomas, B.N.; Amisu, K.O.; Obi, C.L. (2002). Human campylobacteriosis in developing countries. Emerg. Infect. Dis., 8, 237-243.

5. Fernández, H. (1993). Occurrence of thermotolerant species of Campylobacter in three groups of hens maintained under different environmental conditions. Braz. J. Microbiol., 24, 265-2.

6. Fernández, H.; Kahler, K.; Salazar, R.; Rios, M. (1994). Prevalence of thermotolerant species of Campylobacter and their biotypes in children and domestic birds and dogs in Southern Chile. Rev. Inst. Med. Trop., $36,433-436$.

7. Fernández, H.; Martin, R. (1991). Campylobacter intestinal carriage among stray and pet dogs. Rev. Saúde Públ. (São Paulo), 25, 473-475.

8. Fernández, H.; Vera, F.; Villanueva, M.P. (2007). Arcobacter and Campylobacter species in birds and mammals from Southern Chile. Arch. Med Vet., 39, 163-165.

9. Giacoboni, G.I.; Itoh, K.; Hirayama, K.; Takahashi, E.; Mitsuoka, T. (1993). Comparison of fecal Campylobacter in calves and cattle of different ages and areas in Japan. J. Vet. Med. Sci., 55, 555-559.

10. Humphrey, T.; O’Brien, S.; Madsen, M. (2007). Campylobacter as zoonotic pathogen: a food production perspective. Int. J. Food Microbiol., 117, 237-257.

11. Lior, H. (1984). New, extended biotyping scheme for Campylobacter jejuni, Campylobacter coli, and "Campylobacter laridis." J. Clin. Microbiol., 20, 636-640.

12. Padungtod, P.; Kaneene, J.B. (005) ampylobacter in Food Animals and Humans in Northern Thailand. J. Food Prot., 68, 2519-2526.

13. Pan American Health Organization. (2006). EPIDAT 3.1. Epidemiological analysis of tabulated data. http://dxsp.sergas.es/ApliEdatos/Epidat/cas/3.6 Descarga

\section{REFERENCES}


Fernández, H. et al.

14. Stanley, K.; Jones, K. (2003). Cattle and sheep farms as reservoirs of Campylobacter. J. Appl. Microbiol., 94, 104S-113S.

15. Tresierra-Ayala, A.; Bendayan, M.A.; Bernuy, A.; Espinoza, F.; Fernandez, H. (1995). Carriage of the classical thermotolerant Campylobacters in healthy domestic animals from eastern Perú. Rev.

Inst. Med. Trop., 37,537-539.

16. World Health Organization. (2001). The Increasing Incidence of Human Campylobacteriosis. Report and Proceedings of a WHO Consultation of Experts. WHO/CDS/CSR/APH/2000.4., 137p. 